\title{
CONTROLE QUÍMICO DA BRUSONE EM ARROZ DE TERRAS ALTAS: EFEITOS NOS FUNGOS NÃO ALVOS DO FILOPLANO ${ }^{1}$
}

\author{
Fábio José Gonçalves², Leila Garcês de Araújo ${ }^{3}$, Gisele Barata da Silva ${ }^{4}$, Marta Cristina Corsi de Filippi ${ }^{2}$
}

\section{ABSTRACT \\ CHEMICAL CONTROL OF UPLAND RICE BLAST: EFFECTS ON FUNGI NOT TARGETED BY PHYLLOPLANE}

Upland rice blast significantly affects yield, requiring one or two fungicides applications to control it. However, the effect of fungicides on beneficial fungi and on fungi not targeted by rice phylloplane are unknown. This study aimed to evaluate the effect of fungicides on panicle blast control, on fungi not targeted by rice phylloplane, and to study the antibiosis of fungi not targeted by $M$. oryzae. A field experiment was conducted by using two cultivars (Primavera and Bonança), four fungicides (trifloxistrobina + propiconazol, azoxistrobina, tebuconazol, and triciclazol) and a control, with a randomized blocks design, in a split-plot scheme, and four replications. The panicle blast severity, leaf chlorophyll content, number of colony-forming units $\mathrm{cm}^{-2}$ of leaf area, and antibiosis were assessed. The Primavera cultivar showed higher panicle blast severity than Bonança. The fungicides azoxistrobina and trifloxistrobina + propiconazol significantly differed from the control, showing the lowest panicle blast severities. The fungicides did not affect the chlorophyll content, but differences were noticed between the cultivars. The fungicides tebuconazol, trifloxistrobina + propiconazol, and azoxistrobina significantly reduced the phylloplane fungi, concerning the control. The triciclazol did not differ from the control, showing the highest number of colony-forming units $\mathrm{cm}^{-2}$ of leaf area. Among the four fungi tested, only Epicoccum sp. showed antagonism to M. oryzae.

KEY-WORDS: Oryza sativa L.; Magnaporthe oryzae (Barr) Couch; biocontrol; antibiosis.

\section{INTRODUÇÃO}

Os agroquímicos são muito utilizados no controle de doenças de plantas, mas a aplicação deles é onerosa e, em alguns casos, pode trazer mais desvantagens do que benefícios (Khan \& Anwer 2011).

\section{RESUMO}

A brusone em arroz de terras altas causa danos significativos, necessitando de uma a duas aplicações de fungicidas, para o controle da doença. No entanto, o efeito de fungicidas sobre fungos não alvos do filoplano do arroz e benéficos são desconhecidos. Este trabalho objetivou avaliar o efeito de fungicidas no controle da brusone nas panículas, sobre fungos não alvos do filoplano de arroz, e estudar a antibiose de fungos não alvos para $M$. oryzae. Foi realizado um experimento em campo, utilizando-se duas cultivares (Primavera e Bonança), quatro fungicidas (trifloxistrobina + propiconazol, azoxistrobina, tebuconazol e triciclazol) e testemunha, com delineamento experimental em blocos ao acaso, em esquema de parcelas subdivididas, e quatro repetições. Foram avaliados a severidade da brusone nas panículas, o teor de clorofila nas folhas, o número de unidades formadoras de colônia $\mathrm{cm}^{-2}$ de folha e a antibiose. A cultivar Primavera apresentou maior severidade de brusone nas panículas do que a Bonança. Os fungicidas azoxistrobina e trifloxistrobina + propiconazol diferiram significativamente da testemunha, com menores severidades de brusone nas panículas. O teor de clorofila não foi influenciado pelo tratamento com fungicida, mas houve diferença entre as cultivares. Os fungicidas tebuconazol, trifloxistrobina + propiconazol e azoxistrobina reduziram significativamente os fungos do filoplano, em relação à testemunha. $\mathrm{O}$ triciclazol proporcionou maior número de unidades formadoras de colônia $\mathrm{cm}^{-2}$ de folha, não diferindo da testemunha. Dos quatro fungos testados, apenas Epicoccum sp. apresentou antagonismo para M. oryzae.

PALAVRAS-CHAVE: Oryza sativa L.; Magnaporthe oryzae (Barr) Couch; biocontrole; antibiose.

Por isto, tem havido aumento de informações sobre o impacto do uso de produtos químicos na agricultura, no ambiente e na saúde humana.

A brusone, causada pelo fungo Magnaporthe oryzae (Barr) Couch [anamorfo Pyricularia oryzae (Cav.)], pode produzir perdas de até $100 \%$, na pro-

1. Trabalho recebido em mar./2011 e aceito para publicação em mar./2012 ( ${ }^{\circ}$ registro: PAT 13565).

2. Embrapa Arroz e Feijão, Setor de Fitopatologia, Santo Antônio de Goiás, GO, Brasil.

E-mails: biofabio_botanico@yahoo.com.br, cristina@cnpaf.embrapa.br.

3. Universidade Federal de Goiás, Instituto de Ciências Biológicas, Departamento de Biologia Geral, Goiânia, GO, Brasil.

E-mail: leilagarcesaraujo@gmail.com.

4. Universidade Federal Rural da Amazônia, Departamento de Fitopatologia, Belém, PA, Brasil. E-mail: gisele.barata@ufra.edu.br. 
dutividade do arroz (Prabhu et al. 2009), sendo a principal doença de arroz no planeta.

O manejo integrado da brusone objetiva controlar a população do patógeno a níveis toleráveis, sem causar danos econômicos à cultura, mediante a adoção de um conjunto de medidas preventivas, de maneira não isolada, como a resistência genética da cultivar, práticas culturais e controle químico (Prabhu \& Filippi 2006).

A utilização de fungicidas no controle de doenças torna-se importante, quando o grau de resistência da cultivar é ineficaz. No manejo integrado da brusone, o fungicida é um componente importante, devido à curta durabilidade da resistência vertical e ao aumento da susceptibilidade das cultivares com resistência parcial, tanto em arroz de terras altas quanto irrigado (Prabhu \& Filippi 2006).

A eficiência da proteção de plantas, pelo uso de fungicidas, está ligada a vários fatores e depende do fungicida utilizado, intervalo de aplicação, número de aplicações, tempo de aplicação, misturas utilizadas e qualidade e tecnologia da aplicação. $\mathrm{O}$ fungicida utilizado deve ser tóxico ao patógeno e ter grande estabilidade metabólica, mesmo nas condições mais adversas de clima. Deve ser de baixo impacto ambiental e não fitotóxico à planta, evitando, assim, danos ao meio ambiente (Azevedo 2001).

O manejo tem como objetivo estabelecer um balanço entre a doença e a cultura no campo e evitar ações desfavoráveis, como o uso indiscriminado de agroquímicos, com possíveis efeitos sobre micro-organismos não alvos. Muitos fungicidas diminuem a atividade antagonista no filoplano, enquanto outros a aumentam. Por isto, um amplo conhecimento dos produtos utilizados é imprescindível para que um resultado eficaz e ecologicamente correto seja alcançado (Prabhu \& Filippi 2006).

A combinação de antagonistas e fungicidas pode ser um dos meios de se otimizar o seu uso, aumentando a sua eficiência e permitindo a inserção do controle biológico em um sistema de manejo integrado de doenças (Duffy 2000, Sanjay et al. 2008).

Diante do exposto, o presente trabalho objetivou avaliar o efeito de fungicidas no controle da brusone nas panículas, sobre fungos não alvos do filoplano de folhas de arroz, e estudar a antibiose de fungos não alvos para $M$. oryzae.

\section{MATERIAL E MÉTODOS}

Foi realizado um experimento de campo, na Embrapa Arroz e Feijão, localizada no município de Santo Antônio de Goiás (GO), no ano agrícola de $2005 / 2006$. O delineamento experimental foi o de blocos ao acaso, em esquema de parcelas subdivididas, com quatro repetições.

Os tratamentos aplicados às parcelas consistiram de duas cultivares de arroz de terras altas (Primavera e Bonança) e as subparcelas foram constituídas por pulverizações com os fungicidas trifloxistrobina + propiconazol, azoxtrobin, tebuconazol, triciclazol e testemunha (água). Cada unidade experimental foi composta por oito linhas de 5,0 m de comprimento, com quatro linhas para cada cultivar, espaçadas em $0,35 \mathrm{~m}$ entre as linhas e $0,50 \mathrm{~m}$ entre as parcelas, sendo a densidade de semeadura de 80 sementes por metro linear.

$\mathrm{Na}$ adubação de plantio, foram aplicados $350 \mathrm{~kg} \mathrm{ha}^{-1}$ da fórmula N-P-K (05-30-15) e, também, foram realizadas duas adubações de cobertura, com $60 \mathrm{~kg} \mathrm{ha}^{-1}$ de nitrogênio, aos 45 e 70 dias após o plantio.

Os fungicidas (i.a ha-1) avaliados foram: trifloxistrobina + propiconazol $(250+250 \mathrm{~mL})$; azoxistrobina $(100 \mathrm{~mL})$; tebuconazol $(150 \mathrm{~mL})$ e triciclazol $(225 \mathrm{~mL})$. A testemunha foi tratada somente com o inseticida carbofuran $\left(20 \mathrm{~kg} \mathrm{ha}^{-1}\right)$, como os demais tratamentos. Os fungicidas foram aplicados em pulverizações foliares, com $250 \mathrm{~L} \mathrm{ha}^{-1}$ de água, utilizando-se um pulverizador costal pressurizado (40 libras) e efetuando-se uma aplicação na emissão de panículas, aos 75 dias após o plantio, e outra dez dias após a primeira.

Foram avaliados a severidade da brusone nas panículas e o teor de clorofila nas folhas. A severidade da brusone nas panículas foi avaliada utilizando-se a escala de seis graus $(0 \%, 5 \%, 25 \%, 50 \%, 75 \%$ e $100 \%$ de espiguetas afetadas), de acordo com Prabhu (1990). A severidade da brusone nas panículas foi avaliada em todas as panículas colhidas em $0,5 \mathrm{~m}$, nas duas linhas centrais de cada parcela. A determinação do teor de clorofila nas folhas foi realizada com o aparelho Minolta SPAD-502, em 20 perfilhos, na última folha aberta, posicionando-se o aparelho no terço superior da folha.

Foram coletadas folhas bandeiras 48 horas após as duas aplicações dos fungicidas, para isolamento dos fungos do filoplano de arroz, através do 
método do imprinting (Leben 1961). Foram retirados $5,0 \mathrm{~cm}$ do terço médio da folha e a superfície adaxial foi pressionada sobre o meio de cultura BDA(Batata-Dextrose-Ágar) acidificado, com três folhas por placa de Petri e 12 folhas por tratamento. As placas foram incubadas em câmara climatizada a $22^{\circ} \mathrm{C}$, na presença de luz, e, após 72 horas, avaliou-se o número de unidades formadoras de colônia (UFC) $\mathrm{cm}^{-2}$ de folha, por placa de Petri. As colônias que se formaram individualizadas e contrastantes, em sua morfologia, foram transferidas para tubos de ensaio, quatro dias após a realização do imprinting.

Para a identificação dos fungos, foram confeccionadas lâminas com parte do micélio e água. Para os fungos que não esporularam no tubo, também foi utilizado o método de esporulação de microcultura de micélio (Sutton 1980). No método de microcultura de micélio, obteve-se o bloco de BDA fino, que foi colocado em cima de uma lâmina esterilizada, dispondo-se parte do micélio em cada lado do bloco, e, em seguida, uma lamínula esterilizada foi posicionada em cima do bloco. As microculturas foram incubadas para crescimento em câmara climatizada a $22^{\circ} \mathrm{C}$, na presença de luz. De cinco a oito dias após ter sido realizada a microcultura, o bloco de BDA foi descartado e a lamínula da microcultura foi utilizada para confecção de uma lâmina em água, e a lâmina da microcultura foi usada para preparar outra lâmina, em $10 \mu \mathrm{L}$ de lactofenol (20 mL de ácido lático, $20 \mathrm{~mL}$ de fenol e $40 \mathrm{~mL}$ de glicerina). A identificação, com relação ao gênero, foi feita através de microscópio ótico, de acordo com Barnett \& Hunter (2003).

No teste de antibiose, foi utilizado, como desafiante, um isolado de M. oryzae, Py-307, obtido da coleção do Laboratório de Fitopatologia da Embrapa Arroz e Feijão. Este isolado, assim como os isolados obtidos do filoplano de arroz, foi repicado para placas de petri contendo meio de cultura BDA acidificado e incubado em câmara climatizada a $22^{\circ} \mathrm{C}$, por quatro dias, na presença de luz, para se obterem os discos de micélio para a antibiose.

$\mathrm{O}$ experimento para a antibiose foi realizado utilizando-se o método da cultura pareada (Romeiro 2007), no qual foram retirados discos de 5,0 $\mathrm{mm}$ de micélio das colônias do patógeno e dos prováveis antagonistas fúngicos e colocados em placas contendo BDA acidificado, em lados opostos, distanciados entre si em, aproximadamente, $3,0 \mathrm{~cm}$, a $2,5 \mathrm{~cm}$ da borda. Utilizou-se o delineamento experimental inteiramente casualizado, com três repetições para cada fungo. Foram utilizadas, também, três placas do isolado de $M$. oryzae, para crescer na ausência do provável antagonista, como testemunha. Após sete dias em câmara climatizada a $22^{\circ} \mathrm{C}$, foi avaliada a antibiose sobre os fungos identificados do filoplano de arroz, observando-se a presença ou não do halo, em comparação com a testemunha.

Os dados da severidade de brusone nas folhas, do teor de clorofila nas folhas e do número de UFC $\mathrm{cm}^{-2}$ de folha foram submetidos a análise de variância e a comparação das médias foi efetuada pelo teste Tukey, a 5\%, com o auxílio do programa estatístico SPSS.

\section{RESULTADOS E DISCUSSÃO}

Houve diferença significativa para cultivares e aplicação de fungicidas, em relação à severidade da brusone nas panículas, com severidade maior na cultivar Primavera (Tabela 1), entretanto, a interação cultivar $\mathrm{x}$ fungicida não foi significativa. Estes resultados estão de acordo com os observados por Prabhu et al. (2003), que utilizaram as cultivares Bonança, Canastra, Caiapó e Primavera, dentre as quais a última apresentou maior severidade de brusone nas panículas tratadas e não tratadas com fungicidas.

O teor de clorofila não foi influenciado pelo tratamento com fungicida $\mathrm{e}$ a interação cultivar $\mathrm{x}$ fungicida não foi significativa, mas houve diferença entre as cultivares, sendo maior na cultivar Primavera (Tabela 1). As severidades de brusone nas panículas foram menores, quando aplicados os fungicidas azoxistrobina e trifloxistrobina + propiconazol (Figura 1).

Os resultados da análise de variância, para o número de UFC $\mathrm{cm}^{-2}$ de folha de fungos do filoplano, evidenciaram que houve diferença significativa entre os fungicidas, entretanto, as cultivares não apresentaram diferenças, assim como não houve

Tabela 1. Severidade de brusone nas panículas e teor de clorofila nas cultivares de arroz Primavera e Bonança (Santo Antônio de Goiás, GO, 2005/2006).

\begin{tabular}{lcc}
\hline \multirow{2}{*}{ Cultivar } & $\begin{array}{c}\text { Severidade de brusone } \\
\text { nas panículas }\end{array}$ & Teor de clorofila \\
\cline { 2 - 3 } & $\%$ & unidade SPAD \\
\hline Primavera & $36,243 \mathrm{a}^{*}$ & $42,635 \mathrm{a}^{*}$ \\
Bonança & $19,045 \mathrm{~b}$ & $36,420 \mathrm{~b}$ \\
\hline * Médias seguidas da mesma letra, na coluna, não diferem entre si, a 5\%, pelo \\
teste Tukey.
\end{tabular}




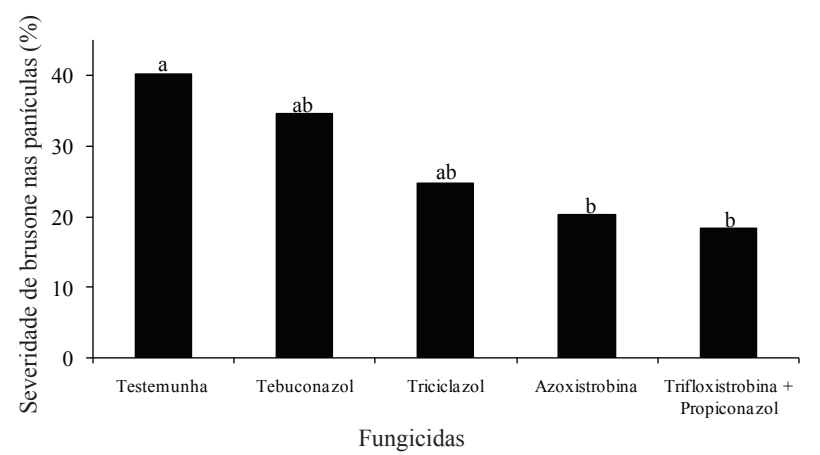

Figura 1. Severidade de brusone nas panículas, nas cultivares de arroz Primavera e Bonança, em função do tratamento com fungicidas (Santo Antônio de Goiás, GO, 2005/2006). Médias seguidas pela mesma letra não diferem entre si, a 5\%, pelo teste Tukey.

interação entre cultivar e fungicidas. Os fungicidas tebuconazol, trifloxistrobina + propiconazol e azoxistrobina reduziram significativamente os fungos do filoplano, em relação à testemunha (Figura 2). Dickinson \& Wallace (1976) também verificaram que a população microbiana da folha bandeira de trigo foi reduzida pela ação de fungicidas. Adetutu et al. (2008) constataram que o azoxistrobina permanece no solo após 21 dias de sua aplicação, diminuindo a diversidade de fungos não alvos de solo.

Em plantas expostas ao fungicida triciclazol, detectou-se maior número de $\mathrm{UFC} \mathrm{cm}^{-2}$ de fungos, não diferindo, contudo, da testemunha, que não foi tratada com fungicida. Portanto, o triciclazol mostrou-se mais seletivo aos fungos não alvos, podendo ser inserido em testes posteriores in vivo, misturados ou não a antagonistas (Figura 2). Estes resultados são promissores porque o triciclazol é sistêmico, sendo o mais usado no controle da brusone no Brasil, atuando na inibição da síntese de melanina (Prabhu \& Filippi 2006).

Resultados de pesquisas sobre os efeitos de fungicidas sobre os micro-organismos do filoplano são conflitantes (Dickinson \& Walpole 1975, Sinclair 1981). O uso de fungicidas, na fase de emissão de panículas, pode controlar outros micro-organismos na folha e atrasar a senescência (Sinclair 1981). Os fungicidas também podem diminuir o potencial do controle biológico de organismos que ocorrem nas folhas e espiguetas (Sinclair 1981). Os dois efeitos devem ser considerados no uso e registro de fungicidas.

Os fungicidas sistêmicos aumentam as exsudações de compostos orgânicos nas folhas, favorecendo

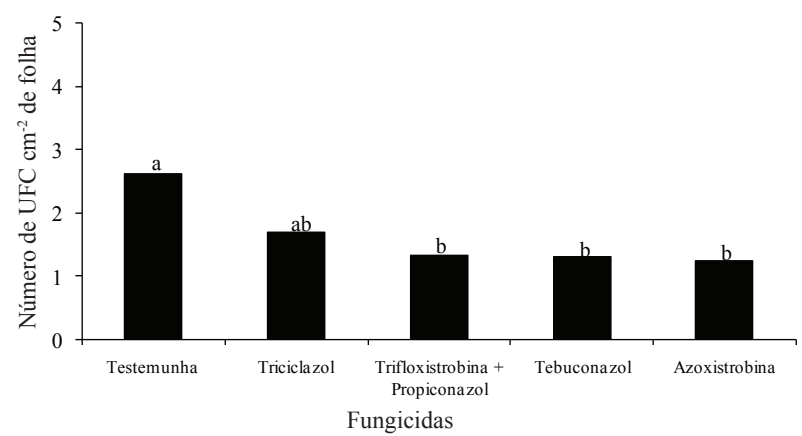

Figura 2. Número de UFC $\mathrm{cm}^{-2}$ de fungos do filoplano isolados de folhas de arroz, 48 horas após duas pulverizações com fungicidas (Santo Antônio de Goiás, GO, 2005/2006). ${ }^{1}$ Médias seguidas pela mesma letra não diferem entre si, a $5 \%$, pelo teste Tukey.

a sua colonização por alguns organismos da microflora e eliminando outros seletivamente (Sinclair 1981). A aplicação de fungicidas sistêmicos também suprime o desenvolvimento de saprófitos nas espiguetas de arroz e nas vagens da soja, aumentando a qualidade das sementes (Sinclair 1981).

Bertelsen et al. (2001) observaram que o tratamento com azoxistrobina reduziu o crescimento micelial de fungos saprofíticos, atrasando a senescência e aumentando a produtividade do trigo de inverno. Wachowska (2005) também observou que os fungicidas azoxistrobina + difenoconazol e clorotalonil diminuíram o crescimento micelial de fungos que colonizavam as folhas de trigo de inverno.

Dentre os 29 gêneros de fungos do filoplano do arroz, Epicoccum sp., Phoma sp., Coniothyrium sp. e Pithomyces sp. foram os mais frequentes e, por isto, foram submetidos ao método de cultura pareada, para examinar a antibiose. Dentre os quatro fungos testados, apenas Epicoccum sp. apresentou halo de inibição para $M$. oryzae, podendo ser usado, futuramente, isoladamente e/ou com triciclazol, em estudos de controle biológico para M. oryzae, em condições de campo. Araújo et al. (2010) também verificaram que Epicoccum sp. isolado de campo experimental, em sistema orgânico de produção de arroz, formou zonas de inibição para $M$. oryzae.

\section{CONCLUSÕES}

1. Os fungicidas azoxistrobina e trifloxistrobina + propiconazol diminuíram a severidade de brusone nas panículas. 
2. A maioria dos fungicidas (trifloxistrobina + propiconazol, azoxistrobina e tebuconazol) afetou os fungos não alvos do filoplano do arroz, exceto o triciclazol, indicando um certo grau de seletividade do mesmo.

3. Epicoccum sp. apresentou ação antagonista para M. oryzae.

\section{AGRADECIMENTOS}

Ao Dr. A. S. Prabhu, pela revisão e valiosas sugestões no manuscrito.

\section{REFERÊNCIAS}

ADETUTU, E. M.; BALL, A. S.; OSBORN, A. M. Azoxystrobin and soil interactions: degradation and impact on soil bacterial and fungal communities. Journal of Applied Microbiology, Oxford, v. 105, n. 6, p. 17771790, 2008.

ARAÚJO, L. G. et al. Antibiose de fungos do filoplano de plantas de arroz a Magnaporthe oryzae. Revista de Biologia Neotropical, Brasília, DF, v. 7, n. 1, p. 1-6, 2010.

AZEVEDO, L. A. S. Proteção integrada de plantas com fungicidas: teoria, prática e manejo. São Paulo: Emopi, 2001.

BARNETT, H. L.; HUNTER, B. B. Illustrated genera of imperfect fungi. 4. ed. St Paul: The American Phytopathological Society, 2003.

BERTELSEN, J. R.; DE NEERGAARD, E.; SMEDEGAARD-PETERSEN, V. Fungicidal effects of azoxystrobin and epoxiconazole on phyllosphere fungi, senescence and yield of winter wheat. Plant Pathology, New Jersey, v. 50, n. 2, p. 190-205, 2001.

DICKINSON, C. H.; WALLACE, B. Effects of late applications of foliar fungicides on activity of microorganisms on winter wheat flag leaves. Transactions of the British Mycological Society, Cambridge, v. 67, n. 1, p. 103-112, 1976.

DICKINSON, C. H.; WALPOLE, P. R. The effect of late application of fungicides on yield of winter wheat. Experimental Husbandary, London, v. 29, n. 1, p. 23-28, 1975.

DUFFY, B. Combination of pencycuron and Pseudomonas fluorescens strain 2-79 for integrated control of rhizoctonia root rot and take-all of spring wheat. Crop Protection, Oxford, v. 19, n. 1, p. 21-25, 2000.
KAWAMATA, H.; NARISAWA, K.; HASHIBA, T. Suppression of rice blast by phylloplane fungi isolated from rice plants. Journal of General Plant Pathology, Tokyo, v. 70, n. 2, p. 131-138, 2004.

KHAN, M. R.; ANWER, M. A. Fungal bioinoculants for plant disease management. In: AHMAD, I.; AHMAD, F.; PICHTEL, J. Microbes and microbial technology. New York: Springer, 2011. p. 447-488.

LEBEN, C. Microorganisms on cucumber seedlings. Phytopathology, St. Paul, v. 51, n. 1, p. 553-557, 1961.

PRABHU, A. S. Misturas de cultivares no controle da brusone nas panículas em arroz de sequeiro. Pesquisa Agropecuária Brasileira, Brasília, DF, v. 25, n. 8, p. 11831192, 1990.

PRABHU, A. S. et al. An unprecedented outbreak of rice blast on a newly released cultivar BRS Colosso in Brazil. In: WANG, G. L.; VALENT, B. Advances in genetics, genomics and control of rice blast. Amsterdam: Springer Science, 2009. p. 257-267.

PRABHU, A. S. et al. Estimativa de danos causados pela brusone na produtividade de arroz de terras altas. Pesquisa Agropecuária Brasileira, Brasília, DF, v. 38, n. 9, p. 10451051, 2003.

PRABHU, A. S.; FILIPPI, M. C. C. Resistência da cultivar no manejo integrado da brusone. In: PRABHU, A. S.; FILIPPI, M. C. C. Brusone em arroz: controle genético, progresso e perspectivas. Santo Antônio de Goiás: Embrapa Arroz e Feijão, 2006. p. 323-387.

ROMEIRO, R. S. Prospecção da potencialidade antagonística de possíveis agentes de biocontrole. In: ROMEIRO, R. S. Controle biológico de doenças de plantas: procedimentos. Viçosa: UFV, 2007. p. 95-122.

SANJAY, R.; PONMURUGAN, P.; BABY, U. I. Evaluation of fungicides and biocontrol agents against grey blight disease of tea in the field. Crop Protection, Oxford, v. 27, n. 3-5, p. 689-694, 2008.

SINCLAIR, J. B. Fungicide sprays for the control of seedborne pathogens of rice, soybeans and wheat. Seed Science and Technology, Zurich, v. 9, n. 3, p. 697-705, 1981.

SUTTON, B. C. The coelomycetes. London: Commonwealth Mycological Institute, 1980.

WACHOWSKA, U. The role of pesticides in the development of populations of microorganisms colonizing the leaves of winter wheat. Polish Journal of Environmental Studies, Olsztyn, v. 14, n. 1, p. 95-102, 2005. 